\title{
The Activity of PVDF-TiO2/ZnO/CoO Nanofiber Photocatalyst for Degradation of Humic Acid Solution
}

\author{
Siti Oryza Sativa ${ }^{1}$, Muhammad Ali Zulfikar $^{2}$, Ervin Tri Suryandari ${ }^{3}$, Muhammad Nasir $^{4}$ \\ \{ sitioryzasativa@gmail.com¹, zulfikar@chem.itb.ac.id ${ }^{2}$,ervin_ts@walisongo.ac.id ${ }^{3}$ \} \\ Laboratory of Analytical Chemistry, Department of Chemistry, Bandung Institute of Technology, \\ Bandung 40132, Indonesia ${ }^{1}$, Analytical Chemistry Research Division, Bandung Institute of Technology, \\ Bandung 40132, Indonesia ${ }^{2}$, Department of Chemistry, Science and Technology Faculty, UIN \\ Walisongo, Semarang ${ }^{3}$
}

\begin{abstract}
Peat water sources could be found in many lowland and marshy areas in Indonesia such as in Sumatra, Kalimantan, and Papua. The water could be a problem for residents living around it because it formed from decayed plants, animals, and microbes. The main component of it is humic acid which is a complex of organic compound and natural polymer. This research aims to conduct the activity of PVDF-TiO2/ZnO/CoO nanofiber photocatalyst for degradation of humic acid solution. Photocatalytic activities were studied inside a photoreactor with artificial UV radiation with $254 \mathrm{~nm}$ wavelength. The percentage of degradation was determined by measuring humic acid solution before and after degradation using UV-Vis spectrophotometer with maximum lambda is $219 \mathrm{~nm}$. The study of kinetic for a photocatalytic reaction was calculated with rate constant 4,29 $\mathrm{x}$ 10-5 min-1 ppm-1 and the kinetic of photodegradation on this research was pseudo secondorder kinetic model.
\end{abstract}

Keywords: Nanofiber, Photocatalyst, Photocatalytic Activity, TiO2, Humic Acid

\section{Introduction}

Indonesia is a country that has quite extensive peatlands which spread across several large islands such as Sumatra, Kalimantan, and Papua. The total area of peatlands in Indonesia is estimated at about 14,90 million hectares which places Indonesia into the fourth country that has extensive peatlands after Canada, Russia, and the United States [1],[2]. The largest peatland area is found on Sumatra Island. One of the problems that often experienced by residents living in peatland areas is the lack of availability of clean water as peatlands produce peat water. Humic acid is one of the main components contained in peat water and a complex organic compound formed from the degradation of plants, animals, and microbes. Generally, humic acid has acidic properties, colored in brown-yellowish, and is dissolved in surface water and groundwater. The acidic property is derived from the carboxylic group function and hydroxyl phenol groups [3].

Some research has been carried out to treat humic acid in biological, physical, or chemical treatment. For an instant, some of the research that has been done to treat humic acid is degradation of humic acid by the litter-decomposing basidiomycete Collybia dryophila [4], adsorption by modification of activated carbon [5], and photocatalytic degradation [6],[7]. However, biological processes are ineffective and other processes only change the liquid waste phase into solid-phase so further processing is needed [8]. One of the effective wastewater 
treatments is by using photocatalyst. The process of photocatalysis has great potential as an inexpensive technology that complies with the concept of zero waste. In the photocatalytic process, light energy is converted to chemical energy to produce hydroxyl radicals which will oxidize organic compounds into carbon dioxide and hydrogen dioxide [9]. This process produces compounds that environmentally friendly and harmless reaction products. Titanium dioxide is commonly used as a semiconductor material for photocatalysis process as it is relatively inexpensive, very efficient, has high stability, and low toxicity [10]. Previously, studies of photodegradation of PVDF/TiO2 and PVDF-ZnO/Ag2CO3/Ag2O nanofiber were reported to degrade toxic pollutants [11],[12]. As a result, these materials have maintained a relatively high photocatalytic activity, which made them as promising candidates for photocatalytic applications and degrading organic pollutants. In this work, PVDF$\mathrm{TiO} 2 / \mathrm{ZnO} / \mathrm{CoO}$ nanofiber photocatalyst activity was studied for the photodegradation of humic acid solution.

\section{Experimental}

Nanofiber photocatalyst that used in this research was obtained from the laboratory of Analytical Chemistry, Department of Chemistry, Bandung Institute of Technology. It was contained $24 \% \mathrm{PVDF}$ and $4 \% \mathrm{TiO} 2 / \mathrm{ZnO} / \mathrm{CoO}$ nanocomposite. In this research, PVDF$\mathrm{TiO} 2 / \mathrm{ZnO} / \mathrm{CoO}$ nanofiber photocatalyst was contacted to humic acid solution under UV light source inside a photoreactor system [13]. A total of $50 \mathrm{~mL}$ of $25 \mathrm{ppm}$ humic acid solution at $\mathrm{pH}$ 3 was put into a breaker glass. An amount of $0,03 \mathrm{gr}$ of nanofiber PVDF-TiO2/ZnO/CoO was added to the breaker glass that contained humic acid solution. The breaker glass was put inside a photoreactor system. The solution of humic acid was stirred under the dark conditions for 20 minutes. After that, the solution was irradiated under 30 Watt of UV light sources with monochromatic rays in $254 \mathrm{~nm}$ wavelength. The distance of the light source to the surface of humic acid solution was $20 \mathrm{~cm}$. After photodegradation process, the remaining of humic acid solution was determined by using UV-Vis spectrophotometer. The maximum lambda of humic acid was $219 \mathrm{~nm}$.

\section{Results and Discussions}

\subsection{The Characteristics of Nanofiber Photocatalyst}

Nanofiber photocatalyst of PVDF-TiO2/ZnO/CoO has been characterized by FTIR and SEM analysis. The result of FTIR spectrum and SEM images can be seen in Figure 1 and Figure 2 respectively. As a result of the analysis, it shows that nanofiber photocatalyst has been successfully synthesized. 


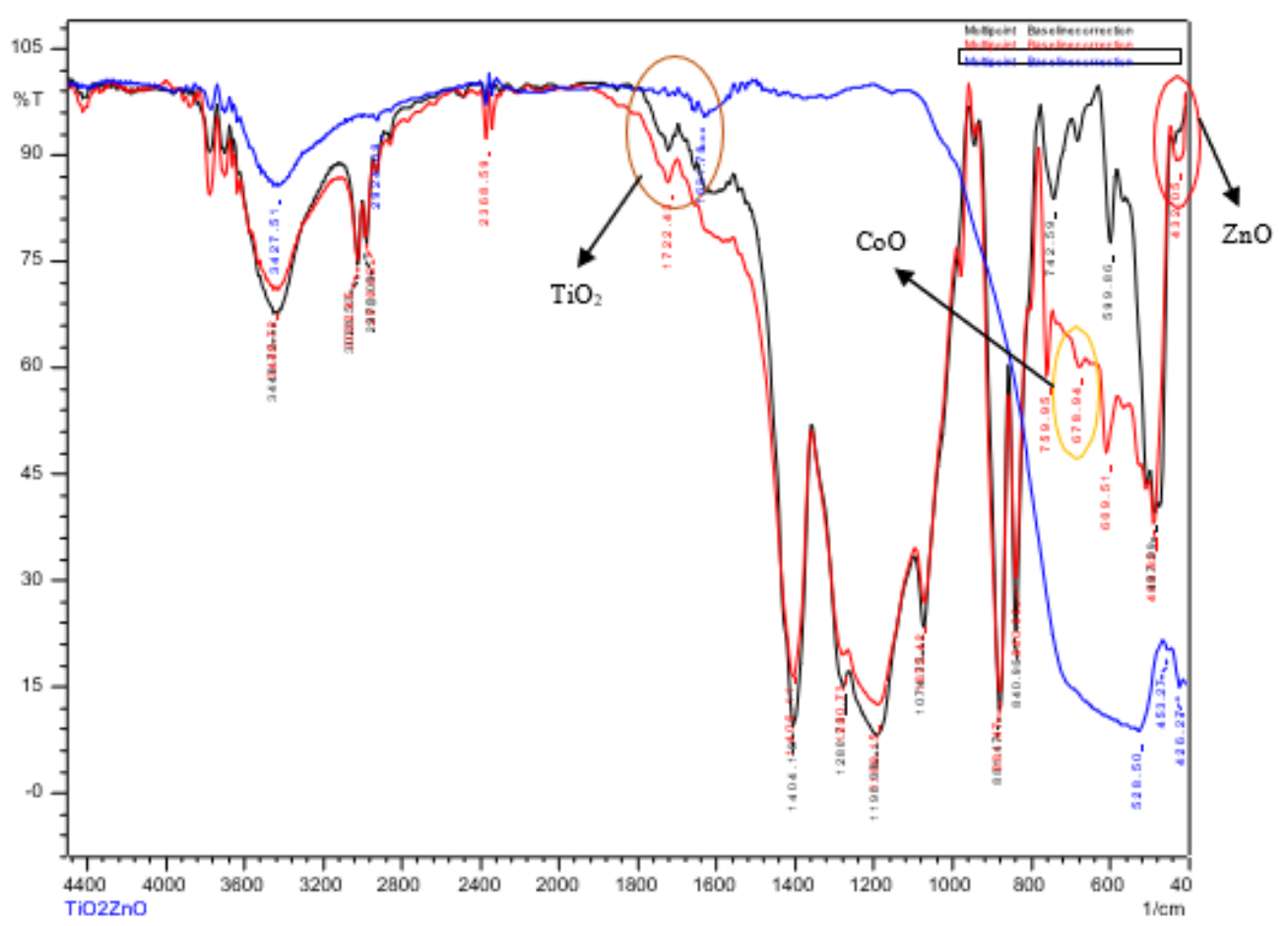

Fig. 1. FTIR Spectrum.

From FTIR spectrum, the black line refers to pure PVDF, the blue line refers to $\mathrm{TiO} 2 / \mathrm{ZnO} / \mathrm{CoO}$ nanocomposite and the red line refers to $\mathrm{PVDF}-\mathrm{TiO} / \mathrm{ZnO} / \mathrm{CoO}$ nanofiber. The peak of cubic $\mathrm{CoO}$ after heat treatment at $800^{\circ} \mathrm{C}$ appeared at $687,94 \mathrm{~cm}-1[14]$. The peak at $1722,43 \mathrm{~cm}-1$ was related to $\mathrm{TiO} 2$. The peak of stretch vibration of $\mathrm{ZnO}$ was observed at 432,05 $\mathrm{cm}-1[15]$.

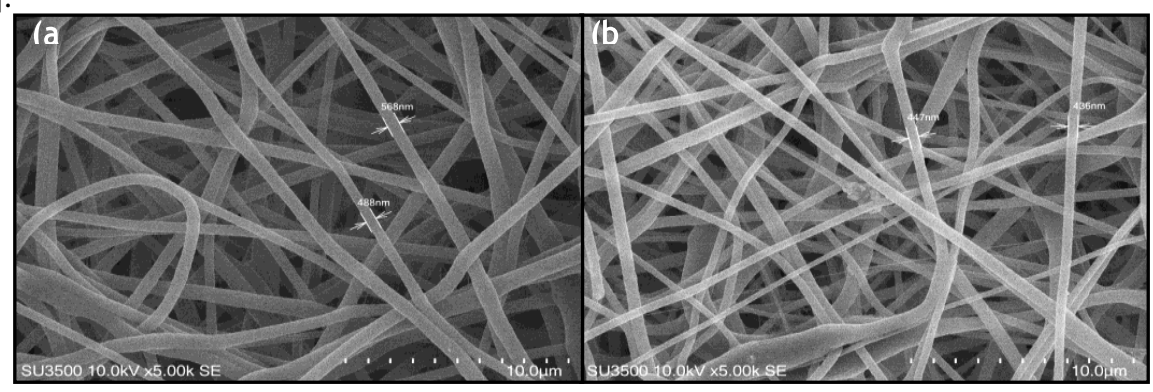

Fig. 2. SEM images: (a) pure PVDF and (b) $\mathrm{PVDF}-\mathrm{TiO}_{2} / \mathrm{ZnO} / \mathrm{CoO}$.

\subsection{The Photodegradation Activity of Humic Acid Solution}

After contacted PVDF-TiO2/ZnO/CoO nanofiber photocatalyst to humic acid solution, the remaining humic acid concentration was determined by using UV-Vis spectrophotometer at certain times. The graph of degradation percentage against degradation times is shown in Figure 
3. It shows that as the time of degradation increases, the percentage of humic acid degradation also increases.

\section{PVDF-4\% $\mathrm{TiO}_{2} / \mathrm{ZnO} / \mathrm{CoO}$}

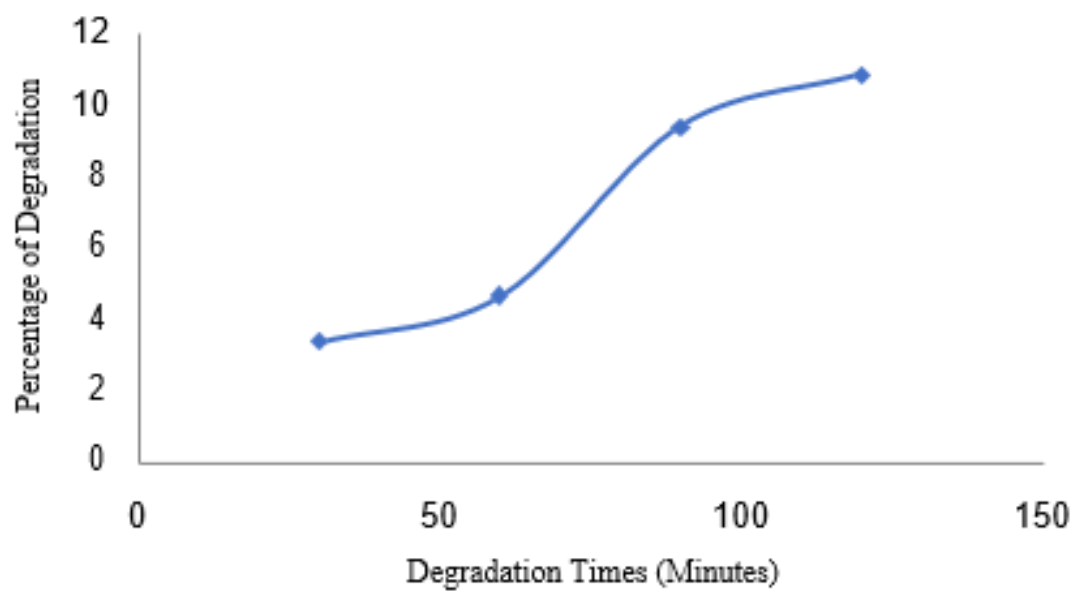

Fig. 3. The graph of photodegradation activity of the humic acid solution.

\subsection{Kinetic Study of Photocatalytic Degradation}

The kinetics study of photocatalytic degradation is one of the factors that have an important role in determining the optimum conditions for photodegradation process. From analyzing kinetic models, the rate constant will be known. The higher value of rate constant, the more effective photocatalytic degradation process. The kinetic study of photocatalytic reaction was carried out by calculating pseudo first-order kinetic model and pseudo second-order kinetic model reactions using Lagergren's model. First-order reaction formula is expressed through equation (1)

$$
\ln C_{0}-C=\ln C_{0}-K_{\text {photocatalytic }} t
$$

and as for second pseudo order reaction shows at equation (2)

$$
\frac{t}{C}=\frac{1}{K_{\text {photocatalytic }} \mathrm{Co}^{2}}+\frac{t}{\mathrm{Co}}
$$

In this equation, $\mathrm{C}$ is referred to the absorbed concentration of humic acid solution in ppm, $\mathrm{C} 0$ is the concentration of initial humic acid solution in $\mathrm{ppm}$, and $\mathrm{t}$ is the degradation time in minutes.

Figure 4 depicts the plots of the $\mathrm{t} / \mathrm{C}$ against the degradation time for nanofiber PVDF$\mathrm{TiO} 2 / \mathrm{ZnO} / \mathrm{CoO}$ photocatalyst, whereas Figure 5 shows the plots of $\mathrm{t} \ln (\mathrm{C} 0-\mathrm{C})$ against the degradation time for nanofiber PVDF-TiO2/ZnO/CoO photocatalyst. 


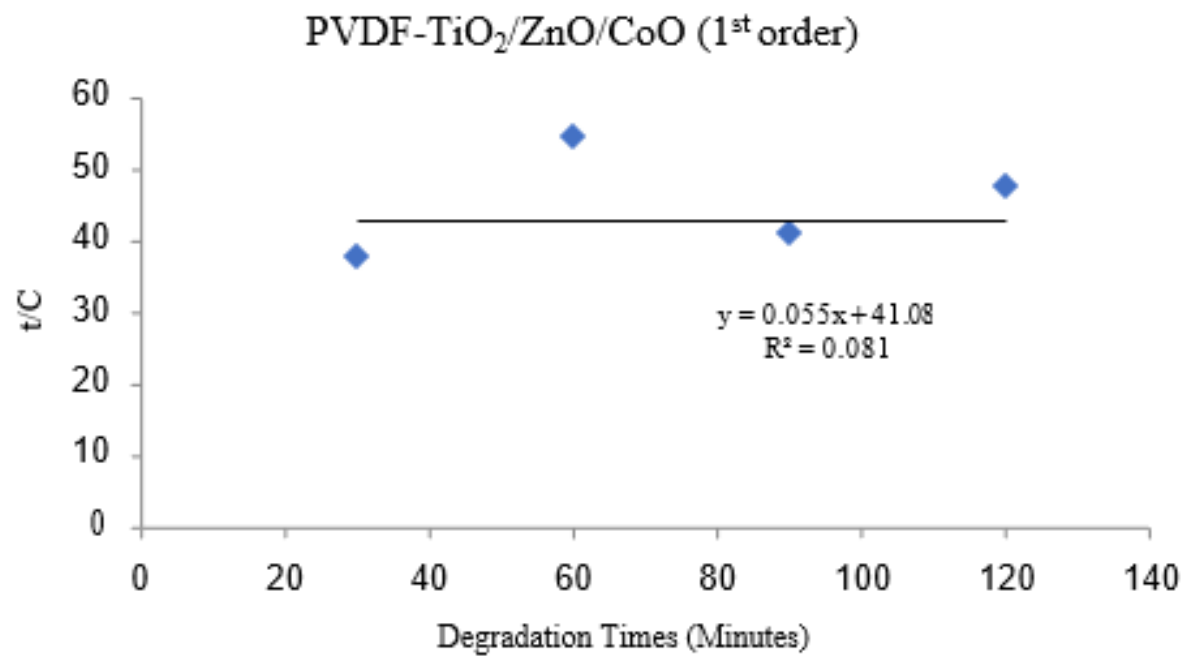

Fig. 4. The graph of pseudo first-order kinetic model.

$$
\mathrm{PVDF}-\mathrm{TiO}_{2} / \mathrm{ZnO} / \mathrm{CoO}\left(2^{\text {nd }} \text { order }\right)
$$

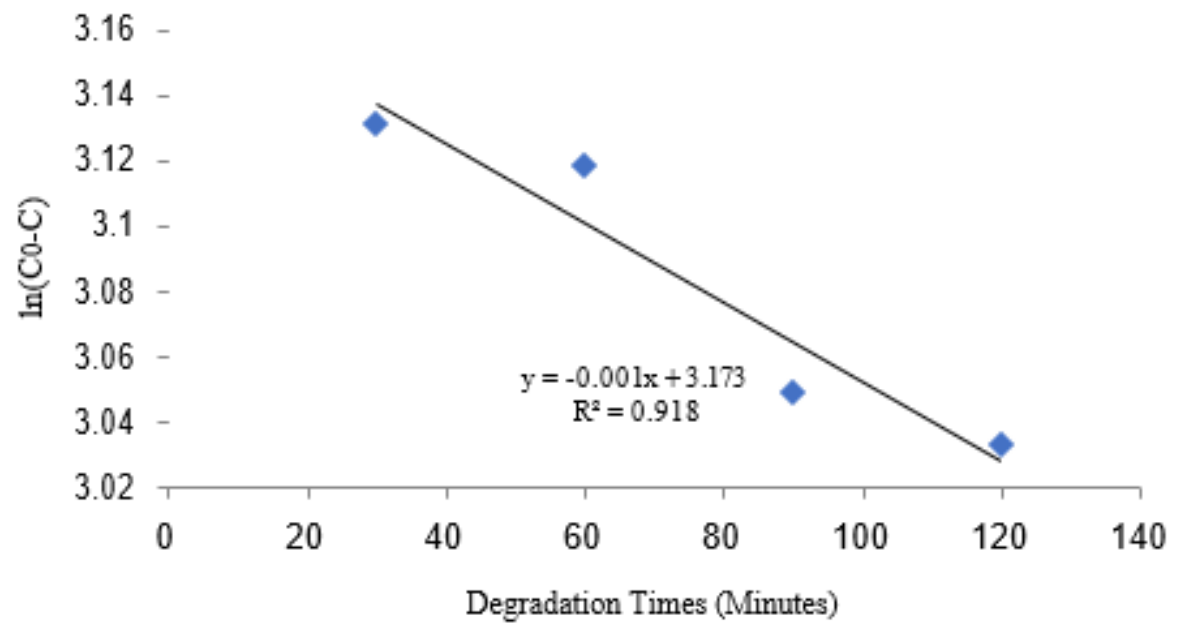

Fig. 5. The graph of pseudo second-order kinetic model.

From the Figure 4 and Figure 5, it shows that the value of R2 for pseudo second-order kinetic model is greater than the pseudo first-order kinetic model so by that it can be concluded that the photocatalytic activity of PVDF-TiO2/ZnO/CoO nanofiber photocatalystfollows the pseudo second-order kinetic model. The rate constant of photocatalytic reaction could be calculated from the slope and the intercept of the graph. The rate constant was calculated and the result was 4,29 x 10-5 min-1 ppm-1. 
To compare with other materials, Table 1 shows several studies of photocatalytic degradation of humic acid solution. From the table, it concluded that the rate constant of photocatalytic degradation of humic acid on this research might be lower than other literature. Furthermore, study the optimum condition has to be done for further research.

Table 1. Kinetic studies of humic acid photocatalytic degradation.

\begin{tabular}{lll}
\hline \multicolumn{1}{c}{ Materials } & $k$ & References \\
\hline PMMA/PVDF & $0,049-0,128 \mathrm{~g} \cdot \mathrm{mg}^{-}$ & {$[16]$} \\
& ${ }^{1} \cdot \mathrm{min}^{-1}$ & \\
iron-modified & $0.00903 \pm 1.07462$ & {$[17]$} \\
pillared & $10^{-4}$ & \\
montmorillonite & & \\
powder & & \\
$100 \mathrm{kDa} \mathrm{HA}$, & $2,18 \times 10^{-2} \mathrm{~min}^{-1}$ & \\
$\mathrm{NPOC}: 4.67 \mathrm{mg}$ & & \\
$\mathrm{L}^{-1}$ & & \\
$\mathrm{Ce}-$ doped $\mathrm{ZnO}$ & & \\
\hline
\end{tabular}

\section{Conclusions}

In summary, humic acid solution has been contacted to PVDF-TiO2/ZnO/CoO nanofiber photocatalyst under UV light source inside a photoreactor system. The photodegradation of humic acid increases with increasing the time of degradation. The kinetic study of photodegradation of humic acid by using PVDF-TiO2/ZnO/CoO nanofiber as photocatalyst described by the pseudo second-order kinetic model with rate constant is 4,29 $\mathrm{x} 10-5$ min-1 ppm-1. From this preliminary study, the PVDF-TiO2/ZnO/Co nanofiber photocatalyst can be used as photocatalyst to degrade humic acid solution but for further research, the amount of nanocomposite should be added up to various percentage to increase the degradation activity and the optimum condition of photocatalytic degradation must be studied.

Acknowledgments. The authors are highly thankful to laboratory of Analytical Chemistry, Bandung Institute of Technology.

\section{References}

[1] Ritung S., and Sukarman: Conformity of peatlands for agriculture. Lahan Gambut Indonesia Pembentukan, Karakteristik, dan Potensi Mendukung Ketahanan Pangan. pp. 61-83 (2016)

[2] Masganti, Anwar. K., and Susanti, M.A.: Potential and utilization of shallow peatland for agriculture. Jurnal Sumberdaya Lahan. Vol. 11 No. 1, pp. 44-52 (2017)

[3] Andayani, W., and Bagyo, A.: TiO2 beads for photocatalytic degradation of humic acid in peat water. Indonesia Journal of Chemistry, pp. 253-257 (2011)

[4] Steffen, K.T., Hatakka, A., and Hofrichter, M.: Degradation of humic acids by the litterdecomposing basidiomycete Collybia dryophilla. Applied and Environmental Microbiology. pp. 3442$3448(2002)$ 
[5] Eustaquio, H.M.B., Lopes, C.W., Rocha, R.S.D, Cardoso, B.D., and Pergher, S.B.C.: Modification of activated carbon for the adsorption of humic acid. Adsorption Science and Technology Vol. 33. No.2. pp. 117-126 (2015)

[6] Al-Rasheed, R., and Cardin. D.J.: Photocatalytic degradation of humic acid in saline water. part 1. artificial seawater: influence of TiO2, temperature, pH, and air-flow. Chemosphere. Vol. 51. pp. 925933 (2003)

[7] Birben, N.C., Paganini, M.C., Calza, P., and Bekbolet, M.: Photocatalytic degradation of humic acid using a novel photocatalyst: Ce-dopped $\mathrm{ZnO}$. Photochemical and Photobiological Sciences. pp. 24-30 (2017)

[8] Daneshvar, N., Ashassi-Sorkhabi, H., dan Tizpar, A: Decolorization of orange II by electrocoagulation method. Separation and Purification Technology. pp. 153-162 (2013)

[9] Ghaneian, M.T., Tabatabae, M., Morovali, P., Ehrampoush, M.H., and Deghani, A.: Photocatalytic degradation of humic acid by $\mathrm{Ag} / \mathrm{ZnO}$ nanoparticle under UVC irradiation from aqueous solutions. Journal of Community Health Research. Pp. 53-61 (2014)

[10] Carp, O., Huisman, C.L., and Reller, A.: Photoinduced reactivity of titanium dioxide. Progress in Solid State Chemistry. pp. 33-177 (2004)

[11] Lou, L., Wang, J., Lee, Y.J., and Ramkumar, S.S.: Visible light photocatalytic functional TiO2/PVDF nanofibers for dye pollutant degradation. Particle and Particle Systems Characterization. pp. 1-12 (2019)

[12] Rosman, N., Salleh, W.N.W., Aziz, F., Ismail, A.F., Harun, A., Bahri, S.S., and Nagai, K.: Electrospun nanofibers embedding $\mathrm{ZnO} / \mathrm{Ag} 2 \mathrm{CO} 3 / \mathrm{Ag} 2 \mathrm{O}$ heterojunction photocatalyst with enhanced photocatalytic activity. Catalysts. pp. 1-18 (2019)

[13] Zulfikar, M.A., Chandra, A.D., Rusnadi, Setiyanto, H., Handayani, N., and Wahyuningrum, D.: $\mathrm{TiO} 2 / \mathrm{ZnO}$ nanocomposite photocatalyst: synthesis, characterization and their application for degradation of humic acid from aquoeus solution. Songklanakarin Journal of Science and Technology. pp. 1-29 (2019)

[14] Tang, C.W., Wang, C.B., and Chien, S.H.: Characterization of cobalt oxides studied by FT-IR, Raman, TPR, and TG-MS. Thermocimia Acta. pp. 68-73 (2008)

[15] Irnameria, D.: Photodegradation of methylene blue dye using $\mathrm{TiO} / \mathrm{ZnO} / \mathrm{CoO}$ nanocomposite photocatalyst, pp. 20. Bandung Institute of Technology Master Thesis, Indonesia (2017)

[16] Zulfikar, M.A., Afrianingsih, I., Bahri, A., Nasir, M., Alni, A., and Setiyanto, H.: Removal of humic acid from aqueous solution using dual PMMA/PVDF composite nanofiber: kinetics study. IOP Conf. Series: Journal of Physics. pp. 1-6 (2018)

[17] Benlemmane, W., Naceur, M.W., and Soukane, S.: Removal of humic acids on iron pillared clay suspensions by ultrafiltration/photocatalysis hybrid method. Journal of Materials and Environmental Sciences. pp. 1683-1691 (2018)

[18] Birben, N.C., Paganini, M.C., Calza, P., and Bekbolet, M.: Photocatalytic degradation of humic acid using novel photocatalyst: Ce-doped $\mathrm{ZnO}$. Photochemical and Photobiological Sciences. pp. 1-7 (2016) 